\title{
THE DEVELOPMENT OF VOLUNTARY MOVEMENT.
}

\author{
BY PROFESSOR E. A. KIRKPATRICK.
}

Filchburg, Mass.

The work of a train dispatcher who has to direct the movements and stoppages of a few score of trains so that there will be no delays or collisions is justly regarded as very difficult, and the brightest minds must go through years of training before they are equal to the task. The child, however, who gets up from his play and brings us a book, and then resumes his seat, performs an act of much greater complexity and nicety of adjustment, for as large a number of muscles as trains are moved, and an impulse passes to and from each muscle; all these movements and adjustments take place in a few seconds, and a variation of a fraction of a second in the order of contraction interferes with the grace and accuracy of the movements as much as the variation of a fraction of an hour in the time of trains interferes with their successful movement.

Without previous practice, pigs, chickens and many other animals can coördinate visual sensations and movements so as to walk or run, avoiding obstacles and adapting themselves to the nature of the ground. Young chickens can move towards and pick up food with only a little less accuracy than adult chickens. The human infant has not such power of motor control at birth, and our problem is to determine how he comes into possession of it within a year or two. First, it is popularly thought that he learns how to make the movements; second, it may be claimed that the power to make such movements is inherited, just as it is in the case of the chicken, except that the mechanism is not complete for some time after birth, as is known to be the case with birds as regards flying; third, it may be claimed that the movements are partially provided for by the inherited mechanism and partly acquired and learned. 
As to the first supposition, the evidence is overwhelmingly against the possibility of such a stupendous task being performed by a child in the short space of a few years. He has over four hundred muscles, and these may be combined in practically an infinite number of different ways. If it depended entirely upon chance or the child's ingenuity whether he should find the right combination for any movement, as reaching for a ball and passing it from one hand to the other, he might work during his whole lifetime at that one puzzle before he would be likely to solve it by getting exactly the right muscles and in the right combinations.

The second theory, though contrary to ordinary observation and opinion, has many facts to support it. For example, it is well known that children and even adults who have never learned to swim sometimes succeed in swimming ashore when left in the water with nothing to do but sink. Fathers sometimes use this method of teaching their sons to swim. Many parents have noticed that their children learned to walk and run with surprising rapidity after they began. The most striking instance of this kind coming under my notice is thus described for me by the father, Supt. Hall, of North Adams, Mass.

"In reply to yours of March 25th, I give you the following account of how my little daughter Katherine learned to walk. She was the youngest of a family of five. The other children had learned to walk soon after they were a year old, and in the normal fashion by being encouraged to put forth a series of efforts until they were able to go alone. Katherine was a normal child in other respects, bright, active and healthy, yet unable to walk a step when she was seventeen months old: Of course, we were anxious, fearing that the cause of this inefficiency might be physical, especially as she persisted in crawling and absolutely refused to try to help herself under the encouragement of any assistance.

"At last we referred the matter to a physician, who said: 'It is a peculiar case, and I can hardly tell whether the diffculty is physical or mental. If there is no improvement in a short time, call me again.' Shortly afterwards I came home 
one day at noon, and, placing my cuffs on a table in the sittingroom, threw myself on a lounge to rest. Katherine happened to notice the cuffs from where she sat on the floor, and, crawling across the room, pulled herself up by the leg of the table, and, reaching out with one hand while she held on to the table with the other, took a cuff off from the table and slipped it on over her wrist. Of course, to do this she had to stand alone. I noticed it at once, and was surprised when she reached out her other hand for the other cuff and slipped that on, and then stood looking in a very interested way at the cuffs on both wrists. Then, to our great surprise, she turned towards me with a very pleased expression on her face and walked as confidently and easily as any child could. Not only this, but she immediately ran across the room, through another room and around through the hall-way, not simply walking, but running as rapidly as a child four or five years of age would. What surprised us most was that she did not seem to be wearied by her effort at all.

"We allowed her to keep the cuffs on for ten minutes or more, and she was on her feet all the time. At last she sat down a moment, rested, and then, strange to say, got up on both feet without assistance and commenced to run around the room again. As an experiment, I took the cuffs off, and she was as unwilling to try to walk as before. We could not possibly induce her to take a single step without the cuffs. When, however, we allowed her to put them on, she seemed to be greatly delighted and walked and ran as before. The result was that I gave her an old pair of cuffs to put on and allowed her to wear them for two days. This was the only way we could keep her from crawling. After that time she seemed to be able to get along without the cuffs, and has not crawled any since."

Instances similar to this of sudden acquisition of control of the vocal organs are not unusual. Numerous cases of remarkable movements by somnambulists and by persons frightened or excited are so common that it is sometimes said that instinctive action is more perfect than deliberate action. The fact that such instances are rare, while most children seem to spend considerable time in learning movements, is not positive proof 
that such movements as walking and swimming are not inherited movements. It may be claimed that as fast as the nervous and muscular systems develop the child begins making the movements which when combined with others constitute the movements of walking; but that those movements ordinarily looked upon as practice and regarded as the cause of nervous and muscular development are in reality merely the effect and sign of the hereditary perfectment of the nervous and muscular systems which is going on. Such movements as those of walking and swimming may, therefore, be wholly hereditary, but it seems reasonable to suppose that the development of those movements is hastened and in part produced by practice, and certainly it cannot be claimed that all the various movements of work and play which human beings perform are inherited rather than acquired, especially when it comes to the manipulation of tools.

The third theory is the one more commonly held by psychologists and physiologists, and in a general way is probably the most nearly correct, but in my judgment it needs to be modified in the direction of the last and made much more definite. Observation of young children has shown clearly that the infant inherits the power to make many reflex, instinctive, expressive and impulsive movements, and that these simpler movements are combined in performing the various voluntary movements which he afterwards performs. It seems to be the common opinion that chance and imitation are important factors in effecting such combinations, while some seem to think that the child learns the simpler movements and then by an act of constructive imagination combines them in the proper way to effect his purposes. Professor Baldwin, who has perhaps contributed more than any one else to the subject, has in part eliminated chance by showing that there is a tendency in every organism so to act as to continue, increase or repeat favorable stimuli. The performance, repetition and perfectment of a movement do not, therefore, depend entirely upon the chance production or repetition of the stimulus by the environment, but the tendency in the animal to the circular form of reaction causes the stimulus to be repeated again and again. He does not, however, make sufficiently clear 
the physiological basis of this tendency, and he seems to allow too large an element of chance in the determination of the course of nervous impulses within the organism. When a child repeats again and again a sound, as children so often do in the third quarter of the first year, it must be because the auditory sensory center is in closer connection with the motor center for the vocal organs than with any other motor center; otherwise the limbs would be just as likely to move as the vocal organs. More than this, the sensory center for that sound must be more closely connected with the center for producing it, or else any other sound would be just as likely to be made. There are probably more than a score of muscles concerned in articulation, and only when just the right ones contract in just the right degree will a given sound be produced; hence the number of different combinations mathematically possible is hundreds of millions. It cannot, therefore, be a matter of chance when a child repeats, after a few trials, a sound that he has heard; but it must depend upon physiological structure that makes the path more open between certain auditory centers and corresponding motor speech centers. Again, when a child imitates a movement he sees, it must be because there is a connection between the visual sense center and the motor center for moving the part in a corresponding way. Of course, it is a familiar fact that there is an excess of motor energy set free in all attempts to make new movements, especially in the case of children, which causes many other than the necessary muscles to contract; but physiological openness of certain paths rather than chance determines which movements shall be selected for repetition.

The next point which I wish to emphasize is that there is an inherited physiological space relation between the visual stimulus of an object in a certain position and the muscles for moving to that object. A young chicken succeeds in picking up a grain of meal, not because he mentally judges the direction and distance, but because the visual sensation calls the right muscle into play. In a similar way, a child grasps an attractive object, not because he knows its direction and distance, but because the visual sensation calls the proper muscles into play. So accurate is this physiological relation between visual sensations and move- 
ments that, though I experimented frequently from the time she began to grasp at about three months, I never succeeded in getting my little girl to try to grasp an object more than four or five inches beyond her reach, and rarely so far as that. She would stretch her hands towards more distant objects that she wanted, but not with the grasping movement. The direction of her movement was also from the first nearly as accurate as the fixation with her eyes. This physiological space relation of certain motor reactions to certain stimulations is, in my judgment, of an importance hitherto unappreciated in explaining not only the development of voluntary movements, but also in explaining ideas of space.

Close observation of the earliest attempts at grasping convinced me that the only element prominent in consciousness at first is the visual sensation of the object. After it has been reached, reflexively grasped when touched and instinctively brought to the mouth several times, disappointment is shown if the hand, instead of the object, comes in contact with the lips, showing that there was then expectation of a certain kind of sensation that was not realized. The young child in grasping objects has a sensation or image of the object in a certain position and an image of a sensation to be gotten; but according to my observations there is no evidence that his consciousness is concerned at all with the movements he is making in order to get hold of the object and bring it to him. The same is true of all the earlier voluntary movements of the child, and attention to the movement itself hinders rather than helps in learning the movement. In the case of Superintendent Hall's little girl there was inability to walk so long as she thought about her movements; but as soon as her attention was concentrated upon getting the cuffs on and carrying them around she succeeded perfectly, though she had never tried it before.

Every adult knows that if he thinks about how he is doing a thing he can do it much less perfectly than when he thinks merely about what he wants to do; yet it is a common belief that one in learning any act must go through a stage of quite acute consciousness of the movements involved. I maintain, on the contrary, that children do not ordinarily go through any 
such stage in learning their earlier movements, and that it is not usually necessary for either children or adults to go through such a stage of consciousness of all, or even of a large proportion, of the elementary movements involved in the new act.

I have not time to give facts in support of this conclusion, nor to point out its importance in the solution of various educational problems ; but I will close with one or two general considerations. In the history of the race arts have always preceded sciences; men have learned to do things, then reflected upon how they do them, analyzed to discover elements, then determined the general laws according to which the actions may be successfully performed, and this order of procedure is the natural one to the child. It is possible that in some cases short cuts may be taken, as Baldwin has suggested, and possibly the order may sometimes be reversed and time saved. A person who knows one language, for example, may possibly learn another language more quickly by studying its grammar first; but I am sure that a child who knows no language could not learn one by beginning with the grammar. Adults who are able to make many movements may learn more quickly a new movement by having attention called to some of the elements, though probably never by having it called to all; but a young child would be hindered rather than helped by such a process. This is true, not simply because of the general tendency of the mind to develop in this order, but because the past experience of the race has developed a very definite system of relations between various stimuli and various simple movements, and has probably developed less definitely various combinations of simple movements and a tendency to other combinations in the attainment of ends frequently striven for by the race. The teaching of a movement by having each of its elements learned, and then having these elements combined and used, is not only a reversal of the natural order in attaining an end and a misdirection of attention, but is an undoing of what has been partially done by the experience of our ancestors, instead of completing the process. 